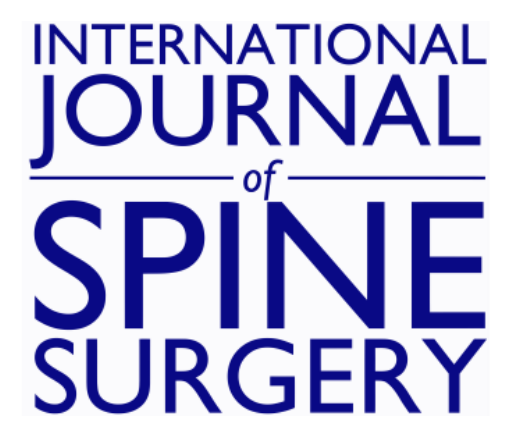

\title{
Perioperative Risks Associated with Cervical Spondylotic Myelopathy Based on Surgical Treatment Strategies
}

Angel Macagno, Shian Liu, Bryan J Marascalchi, Sun Yang, Anthony J Boniello, John A Bendo, Virginie C Lafage and Peter G Passias

Int J Spine Surg 2015, 9 ()

doi: https://doi.org/10.14444/2024

http://ijssurgery.com/content/9/24

This information is current as of April 26, 2023.

Email Alerts Receive free email-alerts when new articles cite this article. Sign up at:

http://ijssurgery.com/alerts

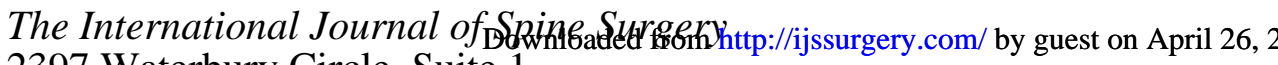
2397 Waterbury Circle, Suite 1,

Aurora, IL 60504, Phone: +1-630-375-1432

(C) 2015 ISASS. All Rights Reserved. 


\section{Perioperative Risks Associated with Cervical Spondylotic Myelopathy Based on Surgical Treatment Strategies}

Angel Macagno, MD, Shian Liu, BS, Bryan J Marascalchi, MD, Sun Yang, BA, Anthony J Boniello, BS, John A Bendo, MD, Virginie C Lafage, PhD, Peter $G$ Passias, $M D$

NY Spine Institute/NYU Medical Center-Hospital for Joint Diseases, New York City, NY

\section{Abstract}

\section{Background}

Few studies have provided nationwide estimates of patient characteristics and procedure-related complications, or examined postsurgical outcomes for patients with cervical spondylotic myelopathy (CSM) comparatively with respect to surgical approach. The objective of this study is to identify patients at risk for morbidity and mortality directly related with the selected approach, report an overall nation-wide complication rate for each approach against which surgeons can compare themselves, and direct future research to improve patient outcomes.

Methods

Patients surgically treated for CSM were retrospectively identified using ICD-9-CM codes from the Nationwide Inpatient Sample (NIS) database. Four cohorts were compared for demographics and hospital system-related data: anterior (ACDF, ACCF), posterior decompression without fusion, decompression with posterior fusion, and combined anterior-posterior. Multivariate analysis was also used to determine the odds ratio of morbidity and mortality among the cohorts.

Results

54,416 discharges were identified between 2001 and 2010: 34,400 anterior, 9,014 decompression procedures without fusion, 8,741 decompression procedures with posterior fusion, and 2,261 combined anterior-posterior. Groups were statistically different with respect to age, length of hospital stay, mortality, and complications. Groups were statistically different for Deyo score except between posterior decompression only and combined approaches. Using multivariate analysis and adjusting for covariates, the combined (2.74[2.18-3.44]) and laminectomy (1.22[1.04-1.44]) cohorts had an increased risk of mortality when compared to anterior alone.

Conclusion

These findings are the first to determine the rates and odds of perioperative risks directly related to combined anterior-posterior procedures. This study provides clinically useful data for surgeons to educate patients and direct future research to improve patient outcomes.

KEYWORDS: CERVICAL SPONDYLOTIC MYELOPATHY, ANTERIOR, COMBINED, LAMINOPLASTY, LAMINECTOMY, PROCEDURE-RELATED COMPLICATIONS, NATION-WIDE TRENDS

VOLUME 9 ARTICLE 24 DOI: 10.14444/2024

\section{Introduction}

Cervical myelopathy is a condition characterized by static and dynamic compression of the cervical spinal cord leading to a variety of neuropathic signs and symptoms. Cord compression may cause myelopathy either by a direct mechanical insult or chronic disruption of vascularization. ${ }^{1}$ As the natural history is commonly a progressive pattern of stepwise deterioration following periods of stable symptoms, ${ }^{2,3}$ early identification and treatment is imperative for optimal results before demyelination and irreversible spinal cord damage occurs. Although some controversy exists in patients with mild to moderate myelopathy, ${ }^{4}$ surgery is typically recommended when clinical and radiologic evidence for CSM exists. Significant symptoms of myelopathy warrant surgical evaluation. $^{5}$

Surgery for degenerative cervical spine disease resulting in CSM is one of the most common inpatient procedures performed in the United States. ${ }^{6}$ There 
are a number of surgical options, including anterior cervical discectomy and fusion (ACDF), anterior cervical corpectomy and fusion (ACCF), laminectomy, laminectomy and fusion, laminoplasty, and combined anterior/posterior procedures. Laminectomy without fusion has a minor role when surgical technique is selected, due to the potential for postlaminectomy kyphosis. ${ }^{7}$

The appropriate choice of procedure must factor in the location of spinal cord compression, number of levels involved, sagittal alignment, instability, associated axial neck pain, risk factors for pseudarthrosis, and patient comorbidities. However, these variables are frequently equivocal, and surgeon training and patient preference are often the deciding factor for treatment rendered. Previous investigations into different cervical techniques fail to show superiority of a specific superior approach ${ }^{8}$ and a recent publication from a large, prospective multicenter study validated the relative equivalence between anterior and posterior treatment for CSM that many spine surgeons think exists. ${ }^{5,9}$ This study, as well as several previous lesser quality series, demonstrate that when the choice of anterior and posterior surgery is decided by the surgeon, patients experience significant, and similar improvements with regard to neurological, functional, and quality-of-life outcomes with comparable and very low rates of neurological complication. ${ }^{9}$ Despite extensive investigation of the middle and longterm neurological and clinical outcomes of this common surgical indication, minimal efforts have been made to quantify the risk of surgical outcomes based on surgical approach and technique.

This study proposes to analyze data from the Nationwide Inpatient Sample (NIS) to best identify disparities in presenting patient characteristics and hospital factors on surgical treatment strategies that were employed to treat patients with CSM. Specifically, this study aims to distinguish these outcome measures among fusion versus decompression strategies, and delve into four separate groups of surgical techniques: anterior fusion (ACDF and ACCF), decompression without fusion (including laminoplasty, laminectomy, laminotomy, and foraminotomy), decompression with posterior fusion and combined anterior-posterior procedure. This study aims to aid physicians in the identification of patients at risk for morbidity and mortality directly related with the selected approach, report an overall nation-wide complication rate for each approach against which surgeons can compare themselves, and direct future research to improve patient outcomes.

\section{Materials and Methods}

\section{Data Source}

The Nationwide Inpatient Sample (NIS) is part of the Healthcare Cost and Utilization Project (HCUP), and is the largest all payer database available in the United States. The NIS is comprised of data from approximately 8 million hospital discharges each year from 45 states, which approximates a $20 \%$ stratified sample of all discharges from US hospitals. For each discharge, the database contains approximately 100 data elements including patient demographics, hospital data (e.g. length of hospital stay, cost, and hospital characteristics), as well as, diagnoses and procedures recorded in International Classification of Disease-9th Revision-Clinical Modification (ICD-9-CM) format. Included weight files provide the ability to determine national estimates.

\section{Inclusion Criteria}

Nationwide Inpatient Sample files from 2001 to 2010 were analyzed. Discharges were identified for those 25 years or older with an ICD-9-CM diagnosis code for cervical spondylosis with myelopathy (721.1). Discharges were divided into four cohorts based on ICD-9-CM procedural codes specifying patients who underwent:

1) anterior cervical discectomy and fusion (ACDF) with and without corpectomy (ACCF) at $\mathrm{C} 2$ or below (either primary 81.02 or revision 81.32 ; excluding posterior cervical fusion procedures both primary 81.03 and revision 81.33),

2) laminoplasty, laminectomy, laminotomy, or foraminotomy (03.09; excluding all fusion and refusions 81.00-81.09 and 81.30-81.39, bone morphogenic protein usage 84.52 , or fusion device usage 84.51) (referred to as "L/F" cohort throughout manuscript) 
3) decompression with posterior fusion of cervical spine at $\mathrm{C} 2$ or Below (either primary 81.03 or revision 81.33; excluding ACDF procedures both primary 81.02 and revision 81.32 )

4) combined anterior and posterior fusion (either primary 81.02 and 81.03 or revision 81.32 and 81.33 )

Discharges with nine or more levels fused or refused (81.64) and lumbar/lumbosacral fusions and refusions (81.06-81.08 and 81.36-81.38) were excluded in order to limit the study to the cervical spine only. Furthermore, any malignancy including lymphoma and leukemia (140.x-172.x, 174.x-195.8, 200.x-208.x), any metastatic solid tumor (196.x-199.1), and all spine fractures open and closed with and without spinal cord injury were excluded in order to prevent confounding factors related to cancer or trauma (805.00-806.9). Lastly, corpectomies (80.99) were excluded from the posterior fusion laminectomy cohort in order to limit this cohort to the posterior column.

\section{Analysis Variables}

Measures included patient demographics and hospital system-related data, incidence of comorbidities, and selected procedure-related complications. Individual comorbidity data was assigned using the Agency for Healthcare Research Quality variables, based on ICD-9-CM codes. ${ }^{10}$ Overall comorbidity burden was calculated using the Deyo Comorbidity Index. ${ }^{11}$ Procedure-related complications were determined using ICD-9-CM codes specifying complications of surgical and medical care. Total complication rate was determined by identifying the occurrence of any procedure-related complication.

\section{Statistical Analysis}

Statistical analysis was performed using R Foundation for Statistical Computing, Vienna, Austria. ${ }^{12}$ Differences in patient and hospital characteristics among the four cohorts were compared using oneway ANOVA with Bonferroni Post Hoc tests. Continuous variables are presented as means and categorical variables as percentages. Two separate multivariate models were used to determine if any of the four procedures included in this study were associated with an increased risk for mortality or morbidity adjusting for the covariates of age, race, gender, Deyo score, and obesity (see Table 4 and Table 7). A p-value of less than 0.05 was considered statistically significant.

\section{Results}

A total of 54,416 discharges were identified between 2001 and 2010, with 34,400 anterior fusions, 9,014 $\mathrm{L} / \mathrm{F}, 8,741$ decompression with posterior fusion, and 2,261 combined anterior and posterior fusions. When categorized by overall surgical strategy, there were 45,402 patients who underwent fusion and 9,014 who underwent decompression only.

\section{Demographics and hospital}

\section{presentation}

Statistically significant differences were found amongst the four surgical approach groups with respect to age, length of hospital stay, and Deyo score (Table 1). For age, all groups were statistically different from one another in every possible combination $(\mathrm{p}<0.0001)$. The laminoplasty cohort was found to be the oldest at 63.4 years old. For length of stay, all groups were statistically different from one another in every possible combination $(\mathrm{p}<0.0001)$. The combined approach was found to have the longest length of hospital stay at 7.5 days. For Deyo score, all groups were statistically different from one another in every possible combination $(\mathrm{p}<0.0001)$, except the difference between the $\mathrm{L} / \mathrm{F}$ and combined cohorts was not statistically significant $(\mathrm{p}>0.05)$. The decompression with posterior fusion cohort had the highest comorbidity burden on presentation with a Deyo score of 0.71 .

Table 1. Baseline demographics and hospital presentation amongst the four
surgical approaches. All cohorts were statistically different from one
another in every possible combination $(p<0.0001)$, except the difference
between the laminoplasty and combined cohorts for Deyo score was not
statistically significant $(p>0.05)$.
\begin{tabular}{|l|r|r|r|r|r|}
\hline & Anterior & $\begin{array}{r}\text { Posterior De- } \\
\text { compression } \\
\text { Only }\end{array}$ & $\begin{array}{r}\text { Decompression } \\
\text { with Posterior } \\
\text { Fusion }\end{array}$ & $\begin{array}{r}\text { Combined } \\
\text { AP }\end{array}$ & P-value \\
\hline Age & 57.5 & 63.4 & 63.0 & 59.6 & $<0.0001$ \\
\hline LOS & 2.8 & 4.7 & 5.8 & 7.5 & $<0.0001$ \\
\hline $\begin{array}{l}\text { Deyo } \\
\text { Score }\end{array}$ & 0.50 & 0.65 & 0.71 & 0.66 & $<0.0001$ \\
\hline
\end{tabular}




\section{Comorbidities}

There were significant differences among patients undergoing the four surgical approaches in specific comorbidities (Table 2). The combined approach group had a significantly higher percentage of anemia, rheumatoid disease, chronic pulmonary disease, coagulopathy, electrolyte imbalance, neurological disorder, renal failure, and pathological weight loss compared to the other surgical approaches $(\mathrm{p}<$ 0.0001).

\section{Perioperative Morbidity}

Regarding complications, all groups were statistically different from one another $(\mathrm{p}<0.0001$, Table 3$)$. The combined anterior/posterior group had the highest total procedure-related complication rate at $27.9 \%$, followed by the decompression with posterior fusion group at $14.7 \%$. All procedures involving a posterior based portion had a higher complication rate than anterior alone.

Using multivariate analysis and adjusting for the covariates of age, race, gender, Deyo score, and obesity, the $\mathrm{L} / \mathrm{F}$, decompression with posterior fusion, and combined AP approaches all had an increased risk of morbidity when compared to anterior techniques alone (Table 4). The combined approach cohort had more than a fivefold increased risk of morbidity when compared to anterior techniques alone.

The analysis of individual complications (Table 5) revealed that the combined approach was found to

Table 3. Total procedure-related complication rate between the surgical approach groups.

\begin{tabular}{|l|r|r|r|r|}
\hline Anterior & $\begin{array}{r}\text { Posterior Decom- } \\
\text { pression Only }\end{array}$ & $\begin{array}{r}\text { Decompression with } \\
\text { Posterior Fusion }\end{array}$ & $\begin{array}{r}\text { Combined } \\
\text { AP }\end{array}$ & P-value \\
\hline $6.3 \%$ & $8.9 \%$ & $14.7 \%$ & $27.9 \%$ & $<0.0001$ \\
\hline
\end{tabular}

Table 2. Baseline comorbidities amongst the four surgical approaches. The cohort with the largest percentage of complications is shaded.

\begin{tabular}{|c|c|c|c|c|c|}
\hline Comorbidity & $\begin{array}{r}\text { Percentage of } \\
\text { Anterior }\end{array}$ & $\begin{array}{r}\text { Percentage of Posterior Decompression } \\
\text { Only Laminoplasty }\end{array}$ & $\begin{array}{r}\text { Percentage of Laminectom Decompression } \\
\text { with Posterior Fusion }\end{array}$ & $\begin{array}{l}\text { Percentage of } \\
\text { Combined AP }\end{array}$ & p-value \\
\hline Anemia & 3.01 & 4.96 & 6.88 & 10.70 & $<0.0001$ \\
\hline $\begin{array}{l}\text { Rheumatoid arthritis/collagen } \\
\text { vascular diseases }\end{array}$ & 2.60 & 2.67 & 5.54 & 5.93 & $<0.0001$ \\
\hline Chronic blood loss anemia & 0.13 & 0.34 & 0.40 & 0.88 & $<0.0001$ \\
\hline Congestive heart failure & 1.97 & 3.48 & 3.78 & 3.27 & $<0.0001$ \\
\hline Chronic pulmonary disease & 15.65 & 16.50 & 17.90 & 18.31 & $<0.0001$ \\
\hline Coagulopathy & 0.69 & 1.22 & 1.51 & 1.86 & $<0.0001$ \\
\hline Diabetes & 16.94 & 20.63 & 21.61 & 18.53 & $<0.0001$ \\
\hline Hypertension & 46.94 & 54.71 & 57.83 & 54.27 & $<0.0001$ \\
\hline Liver disease & 0.50 & 0.79 & 0.86 & 0.75 & $<0.0001$ \\
\hline Electrolyte imbalance & 3.13 & 6.35 & 9.08 & 14.60 & $<0.0001$ \\
\hline Neurological disorder & 3.70 & 4.97 & 5.21 & 5.48 & $<0.0001$ \\
\hline Obesity & 7.42 & 6.79 & 6.97 & 7.21 & $<0.0001$ \\
\hline Peripheral vascular disorders & 1.73 & 2.62 & 2.84 & 2.17 & $<0.0001$ \\
\hline Pulmonary circulation disorders & 0.35 & 0.55 & 1.00 & 0.97 & $<0.0001$ \\
\hline Renal failure & 1.76 & 3.11 & 3.59 & 3.89 & $<0.0001$ \\
\hline Cardiac valvular disorder & 2.45 & 3.01 & 3.25 & 2.96 & $<0.0001$ \\
\hline Pathologic weight loss & 0.54 & 0.81 & 1.30 & 2.30 & $<0.0001$ \\
\hline
\end{tabular}

Downloaded from http://ijssurgery.com/ by guest on April 26, 2023 
have the largest percentage of complications for a majority of the complications included in this study including (from most to least common): adult respiratory distress syndrome, acute post-hemorrhagic anemia, device-related, respiratory, hematoma/seroma, accidental puncture of a vessel or nerve, cardiac, nervous system, venous thrombotic event, postoperative infection, digestive system, wound dehiscence, and post-operative shock complications. The $\mathrm{L} / \mathrm{F}$ cohort was found to have a larger percentage of peripheral vascular and urinary system complications.

\section{Perioperative Mortality}

For mortality, all groups were statistically different from one another in every possible combination $(\mathrm{p}<0.0001)$, except the difference between the anterior and laminoplasty cohorts was not statistically significant ( $p>0.05)$ (Table 6). The combined approach was found to have the highest in-hospital mortality rate at $1.06 \%$. Using a multivariate analysis and adjusting for the covariates of age, race, gender, Deyo score, and obesity, the combined and posterior only approach cohorts had an increased risk of mortality when compared to anterior techniques alone (Table 7). The combined approach cohort had more than a two and a half times increased risk of mortality when compared to anterior techniques alone.

\section{Discussion}

This project sought to compare multiple variables in a large cohort of patients with CSM undergoing different surgical procedures. While indications for the choice of specific surgical procedures are not provided in this database, general trends regarding approach and outcomes can be still gleaned from analysis of this database. Further, the large sample size

Table 4. Multivariate analysis of morbidity using the anterior cohort as the
referent value adjusted for age, race, gender, Deyo score, and obesity.
\begin{tabular}{|l|r|r|r|r|}
\hline Morbidity & $\begin{array}{r}\text { Odds Ra- } \\
\text { tio }\end{array}$ & $\begin{array}{r}\text { Lower } \\
\text { CI }\end{array}$ & $\begin{array}{r}\text { Upper } \\
\text { CI }\end{array}$ & p-value \\
\hline Anterior & - & - & - & - \\
\hline Posterior Decompression Only & 1.30 & 1.24 & 1.36 & $<0.0001$ \\
\hline $\begin{array}{l}\text { Decompression with Posterior } \\
\text { Fusion }\end{array}$ & 2.19 & 2.11 & 2.28 & $<0.0001$ \\
\hline Combined AP & 5.44 & 5.16 & 5.74 & $<0.0001$ \\
\hline
\end{tabular}

provides the statistical power for the identification of perioperative variables associated with the treatment of CSM. To our knowledge, no study has established this important information on such a scale.

The procedures were grouped in decompression techniques alone that included L/F, and decompression with fusion procedures such as anterior fusion (ACDF and $\mathrm{ACCF}$ ), posterior decompression and fusion, and combined anterior/posterior procedures. $\mathrm{ACDF}$ and $\mathrm{ACCF}$ were included in the same group since both offer equivalent treatment strategies and outcomes in the anterior surgical treatment of CSM with high relative effectiveness and similarity of costs and complications. ${ }^{13}$

Anterior approaches were reserved historically for one or two level spondylosis without retrovertebral disease, ${ }^{14}$ but currently the indications extend to 3 or even 4 levels and are generally preferred when restoration of cervical lordosis is the main goal $^{9}$ and when the space occupying effect from spondylosis is located anteriorly. The incidence of perioperative complications is well described depending on choice of surgical approach, ${ }^{15,16}$ but remains unclear after anterior cervical fusion over four or more levels. ${ }^{17} \mathrm{How}-$ ever isolated anterior treatment of 4 or more levels is uncommon and the overwhelming majority of cases represent 1 to 3 levels of treatment. The results on anterior approaches of the current study showed the least amount of complications and morbidity and was consistent with the existing literature: younger patients, with less pre-op comorbidities, shorter LOS and less complication rates when compared to other approaches. ${ }^{9,13,18}$

The high rate of complications of anterior-posterior combined procedures was the most critical finding in our study, with almost one-third of patients experiencing a complication and greater than three times the mortality seen with this surgical approach. The increase in complication rate was significant when compared with anterior or posterior approaches alone (Table 5). This increase was evident for all procedure related complications that included wound dehiscence, hematoma/seroma, postoperative local infections and device related. In part this may be because combined anterior posterior procedures are 
generally indicated for patients with severe kyphosis, severe spinal instability ${ }^{19}$ fixed kyphotic deformity, or complex pathology ${ }^{20}$ that require a more rigid construct to avoid use of postsurgical traction or halo immobilization (Mcafee-Goldstein) (Kim). ${ }^{21,22}$ These circumferential procedures are more technically demanding with significant manipulation of soft tissues and prolonged surgical time and local bleeding.

Table 5. Complications amongst the four surgical approaches. The cohort with the largest percentage of complications is shaded.

\begin{tabular}{|c|c|c|c|c|c|}
\hline Complication & $\begin{array}{r}\text { Percentage of } \\
\text { Anterior }\end{array}$ & $\begin{array}{r}\text { Percentage of Posterior Decompres- } \\
\text { sion Only }\end{array}$ & $\begin{array}{r}\text { Percentage of Decompression with Poste- } \\
\text { rior Fusion }\end{array}$ & $\begin{array}{r}\text { Percentage of Com- } \\
\text { bined AP }\end{array}$ & p Value \\
\hline Device-related & 0.90 & 0.27 & 2.57 & 6.81 & $<0.0001$ \\
\hline Nervous System & 0.45 & 0.82 & 0.90 & 1.46 & $<0.0001$ \\
\hline Cardiac & 0.56 & 0.92 & 1.28 & 1.50 & $<0.0001$ \\
\hline Peripheral Vascular & 0.03 & 0.10 & 0.06 & 0.09 & $<0.0001$ \\
\hline Respiratory & 0.60 & 0.90 & 1.06 & 2.03 & $<0.0001$ \\
\hline Digestive System & 0.30 & 0.36 & 0.41 & 0.62 & $<0.0001$ \\
\hline Urinary & 0.56 & 1.41 & 1.40 & 1.02 & $<0.0001$ \\
\hline Post-op Shock & 0.03 & 0.04 & 0.10 & 0.18 & $<0.0001$ \\
\hline Hematoma/ Seroma & 0.81 & 0.65 & 1.25 & 1.72 & $<0.0001$ \\
\hline Puncture Vessel/ Nerve & 0.56 & 0.92 & 0.92 & 1.59 & $<0.0001$ \\
\hline Wound Dehiscence & 0.02 & 0.14 & 0.23 & 0.31 & $<0.0001$ \\
\hline Postoperative Infection & 0.09 & 0.47 & 0.54 & 0.71 & $<0.0001$ \\
\hline $\begin{array}{l}\text { Acute Post hemorrhagic Ane- } \\
\text { mia }\end{array}$ & 1.05 & 1.87 & 4.24 & 8.23 & $<0.0001$ \\
\hline $\begin{array}{l}\text { Adult Respiratory Distress } \\
\text { Syndrome }\end{array}$ & 1.21 & 1.02 & 2.00 & 9.42 & $<0.0001$ \\
\hline Venous Thrombotic Events & 0.28 & 0.42 & 0.80 & 0.84 & $<0.0001$ \\
\hline
\end{tabular}

Table 6. Comparing mortality rate among the surgical approach groups.

*All cohorts were statistically different from one another in every possible

combination $(p<0.0001)$, except the difference between the anterior

techniques and laminoplasty cohorts was not statistically significant $(p>0.05)$.

\begin{tabular}{|l|r|r|r|r|}
\hline Anterior & $\begin{array}{r}\text { Posterior Decom- } \\
\text { pression Only }\end{array}$ & $\begin{array}{r}\text { Decompression with } \\
\text { Posterior Fusion }\end{array}$ & $\begin{array}{r}\text { Combined } \\
\text { AP }\end{array}$ & P-value \\
\hline $0.33 \%$ & $0.43 \%$ & $0.64 \%$ & $1.06 \%$ & $<0.0001$ \\
\hline
\end{tabular}

Table 7. Multivariate analysis of mortality using the anterior cohort as the referent value adjusted for age, race, gender, Deyo score, and obesity.

\begin{tabular}{|l|r|r|r|r|}
\hline Mortality & $\begin{array}{r}\text { Odds Ra- } \\
\text { tio }\end{array}$ & $\begin{array}{r}\text { Lower } \\
\text { CI }\end{array}$ & $\begin{array}{r}\text { Upper } \\
\text { CI }\end{array}$ & P-value \\
\hline Anterior & - & - & - & - \\
\hline Posterior Decompression Only & 0.88 & 0.74 & 1.06 & 0.186 \\
\hline $\begin{array}{l}\text { Decompression with Posterior } \\
\text { Fusion }\end{array}$ & 1.22 & 1.04 & 1.44 & 0.017 \\
\hline Combined AP & 2.74 & 2.18 & 3.44 & $<0.0001$ \\
\hline
\end{tabular}

Downloaded from http://ijssurgery.com/ by guest on April 26, 2023 
Medically related complications were also higher in the combined group as well, and included post hemorrhagic anemia, respiratory distress syndrome and postoperative shock. Patients who typically benefit from circumferential approaches include patients with medical comorbidities that affect bone quality, such as smoking, diabetes mellitus, osteoporosis, rheumatoid arthritis, and renal dialysis. Poor bone quality limits the ability of stand-alone anterior or posterior fixation devices to maintain correction. ${ }^{19,21,22}$

The combined technique has limited information available in the literature. Available studies compare anterior vs. posterior techniques ${ }^{13,18,23}$ or just posterior approach surgeries ${ }^{24}$ but not circumferential procedures. The current study found most of the patients who underwent this procedure had the second greatest comorbidity burden on presentation overall, with more specific comorbid conditions as well in several categories. The increase in LOS was statistically significant when compared with all the other cohorts and the mortality rate was also increased, more than 2.5 times when compared with the anterior technique alone. The association between severity of comorbidity and surgical treatment approach along with number of complications remains to be studied. However, surgical alternatives should be considered particularly for the highest risk patients. ${ }^{20}$

Another important finding is that patients treated with $\mathrm{L} / \mathrm{F}$ had a marked decrease in length of stay, mortality, and complication rate when compared to posterior decompression and fusion and anteriorposterior procedures, in spite of being the oldest group. When comparing complications between $\mathrm{L} / \mathrm{F}$ and decompression and fusion (Table 5), there was a significant increase in local incidents such as wound hematoma/seroma, wound dehiscence and device related complications, as well as general events such as posthemorragic anemia, postoperative shock, venous thrombotic episodes and respiratory distress syndrome. This remained true when controlling for comorbidities on presentation, which were increased among patients undergoing a laminectomy procedure relative to laminoplasty.

The comorbidity Deyo score in the L/F group was not significantly different from the score found in the anterior-posterior group. Because specific surgical indications and clinical and radiographic details are not available from this registry, further research to determine proper indications for choosing posterior fusion and decompression procedures relative to $\mathrm{L} / \mathrm{F}$ procedures is needed. This is particularly a concern in light of our findings of increased comorbidity burden among the decompression and posterior fusion group on presentation, coupled with the increased procedure related and medical complication rates seen with this approach. Factors including training bias and regional variation should be further evaluated. Additionally, laminectomies performed without fusion were not independently identified as a subset of the L/F cohort in the utilized registry. Therefore, while this analysis displays the validity of laminoplasty, laminectomy, laminoplasty, and foraminotomy as valid surgical options and advocates for their consideration when appropriate, it is not possible to clearly show that laminoplasty alone outperformed laminectomy without fusion, a well-utilized approach. A subsequent breakdown of decompression techniques including laminoplasty from laminectomy without fusions remains to be done to further support our conclusions. ${ }^{25}$ These findings are consistent with a retrospective matched cohort study ${ }^{24}$ that found laminoplasty may be preferable to laminectomy and fusion.

\section{Limitations and Future Work}

The study limitations arise from the construction and availability of NIS data elements. Limitations of the NIS Database are summarized in Table 8. Diagnoses are listed in ICD-9-CM format, and consequently determination of which diagnosis was the primary surgical indication is impossible. This analysis of the NIS database depends on an appropriate use of ICD-9-CM. A single code is often used to cover a number of related procedures or diagnoses, therefore detailed differentiation of these can be challenging. The clear comparison of groups in this study is therefore difficult, due to these potential baseline patient dissimilarities inherent in the database. In our study, the laminoplasty group was identified using ICD-9-CM code 03.09 that includes laminectomy, laminotomy, laminoplasty, exploration of spinal nerve root, and foraminotomy. Exclusion of fusion or fusion-related devices removed the laminectomy with fusion from this cohort to best iso-

Downloaded from http://ijssurgery.com/ by guest on April 26, 2023 
late the laminoplasty cohort. Consequently, the laminoplasty cohort may include a small subset of patients who underwent laminectomy without fusion, a technique which is associated with numerous disadvantages such as postsurgical segmental instability, postsurgical cervical kyphosis, and late neurological deterioration ${ }^{26-29}$; however, if this skewed the data in a significant way, the laminoplasty cohort may actually perform better than our results suggest.

Additionally, there is a wide variation in the invasiveness of decompression procedures that perhaps makes this group too heterogeneous to draw conclusions from.This study suffers from limitations of retrospective analyses and database investigations. Multivariate logistic regression controls for confounders among observed variables, but the absence of prospective randomization precludes a guarantee of equality among unobserved variables. Structure and alignment of the cervical spine is one such unobserved variable of fundamental importance in deciding between surgical approaches, and such information cannot be obtained from administrative databases such as NIS. Furthermore, health related quality of life scores such as the Short-Form 36 were not available, and would have provided invaluable information on the comparative burden of this disease.

To date, there is a paucity of level 1 evidence that differentiates between the surgical techniques. Prior work by Ghogawala et al. explores the feasibility of conducting a randomized control trial, ${ }^{30,31}$ which should be the next steps in improving clinical research in CSM. The associations between the con-

Table 8. Limitations of Database--Nationwide Inpatient Sample from years 2001 to 2010.

\begin{tabular}{|c|c|}
\hline Category & Limitation \\
\hline $\begin{array}{l}\text { Disease } \\
\text { Severity }\end{array}$ & $\begin{array}{l}\text { - Cannot indicate severity of pre-operative CSM } \\
\text { - Cannot identify or weigh differently the variation in neuro- } \\
\text { logic function } \\
\text { assessment of neurologic involvement unavailable } \\
\text { - Presence or absence of myelomalacia is not controlled for }\end{array}$ \\
\hline $\begin{array}{l}\text { Surgical } \\
\text { Approach }\end{array}$ & $\begin{array}{l}\text { Laminoplasty versus laminectomy differentiation using } \\
\text { ICD-9-CM codes is difficult } \\
\text { NIS database does not list the presence nor the type of spinal } \\
\text { instrumentation } \\
\text { NIS database pools together one-level surgeries with multi- } \\
\text { level, including 5-level, operations. } \\
\text { The number of surgical vertebral levels has an impact on out- } \\
\text { comes and it is expected that the combined anterior-posterior } \\
\text { group has the highest number of multilevel cases. }\end{array}$ \\
\hline
\end{tabular}

sidered surgical approaches and outcomes presented in this study should also be explored further in prospective trials to provide clinical information on treatment recommendations. While this study demonstrates increased morbidity based on approach, this study is not necessarily implying conclusions about the indications for approaches. Furthermore, the findings of this study should not be used to determine health policy, but instead should be used to guide future research.

\section{Conclusions}

The NIS is the largest all-payer database available, and provides the statistical power necessary to analyze variables associated with the development and treatment of CSM. Surgical treatment for cervical spondylotic myelopathy involves serious risks, even though it is the standard of care for this pathology. Despite the limitations of this study, these findings are probably the first to recognize and evaluate the severity of perioperative risks directly related to combined anterior-posterior procedures. The association between severity of comorbidity and surgical treatment approach along with number of complications, remains to be reviewed. This study demonstrates higher rates and odds of complications as well as mortality in the decompression with posterior fusion cohort compared to the posterior decompression only cohort for the treatment of multilevel cervical myelopathy using a posterior approach. This study provides clinically useful data for defining expected risk and could help surgeons to educate patients at risk for mortality and morbidity and direct future research to improve surgical outcomes.

\section{References}

1. Karadimas SK, Erwin WM, Ely CG, Dettori JR, Fehlings MG. Pathophysiology and natural history of cervical spondylotic myelopathy. Spine (Phila Pa 1976). 2013;38(22 Suppl 1):S21-36.

2. Nurick $S$. The natural history and results of surgical treatment of the spinal cord disorder associated with cervical spondylosis. Brain.

1972;95(95):101-108. Available at: http://brain.oxfordjournals.org/content/95/1/ 
87.short. Accessed April 19, 2014.

3. Matz PG, Anderson P a, Holly LT, et al. The natural history of cervical spondylotic myelopathy. $J$ Neurosurg Spine. 2009;11(2):104-11. doi:10.3171/ 2009.1.SPINE08716.

4. Kadaňka Z, Bednařík J, Novotný O, Urbánek I, Dušek L. Cervical spondylotic myelopathy: conservative versus surgical treatment after 10 years. Eur Spine J. 2011;20(9):1533-8. doi:10.1007/ s00586-011-1811-9.

5. Fehlings MG, Wilson JR, Kopjar B, et al. Efficacy and safety of surgical decompression in patients with cervical spondylotic myelopathy: results of the AOSpine North America prospective multi-center study. J Bone Joint Surg Am. 2013;95(18):1651-8. doi:10.2106/JBJS.L.00589.

6. Lad SP, Patil CG, Berta S, Santarelli JG, Ho C, Boakye M. National trends in spinal fusion for cervical spondylotic myelopathy. Surg Neurol. 2009;71(1):66-9; discussion 69. doi:10.1016/ j.surneu.2008.02.045.

7. Albert TJ, Vaccaro AR. Postlaminectomy kyphosis. Spine (Phila Pa 1976). 1998;23(24):2738-2745. 8. Yalamanchili PK, Vives MJ, Chaudhary SB. Cervical spondylotic myelopathy: factors in choosing the surgical approach. Adv Orthop. 2012;2012(783762).

9. Fehlings MG, Barry S, Kopjar B, et al. Anterior Versus Posterior Surgical Approaches to Treat Cervical Spondylotic Myelopathy: Outcomes of the Prospective Multicenter AOSpine North America CSM Study in 264 Patients. Spine (Phila Pa 1976). 2013;38(26):2247-52.

10. Healthcare Cost and Utilization Project (HCUP): HCUP Comorbidity Software. Agency Healthc Res Qual. 2014(February 20). Available at: www.hcup-us.ahrq.gov/toolssoftware/comorbidity/ comorbidity.jsp.

11. Deyo RA, Cherkin DC, Ciol MA. Adapting a clinical comorbidity index for use with ICD-9-CM administrative databases. J Clin Epidemiol. 1992;45(6):613-619. Available at: http://www.ncbi.nlm.nih.gov/pubmed/1607900. 12. R Core Team, Team RC. R: A language and environment for statistical computing. 2012. Available at: http://www.r-project.org/.

13. Mummaneni P V. Cervical surgical techniques for the treatment of cervical spondylotic myelopathy.
J Neurosurg Spine. 2009;11:130-141.

14. Geck M, Eismont F. Surgical options for the treatment of cervical spondylotic myelopathy. Orthop Clin North Am. 2002;33(2):329-48.

15. Romano P, Campa D, Rainwater J. Elective cervical discectomy in California: postoperative inhospital complications and their risk factors. Spine Phila Pa 1976. 1997;22(22):2677-92.

16. Wang M, Chan L, Mainman D, Kreuter W, Deyo R. Complications and mortality associated with cervical spine surgery for degenerative disease in the United States. Spine Phila Pa 1976. 2007;32(3):342-7. 17. Huang J, Niu C, Chen L, Lai P, Fu T, Chen W. Anterior cervical spine surgery for multilevel cervical myelopathy. Chang Gung Med J.

2004;27(7):531-41.

18. Shamji MF, Massicotte EM, Traynelis VC, Norvell DC, Hermsmeyer JT, Fehlings MG. Comparison of anterior surgical options for the treatment of multilevel cervical spondylotic myelopathy: a systematic review. Spine (Phila Pa 1976). 2013;38(22 Suppl 1):S195-209.

19. Konig SA, Spetzger U. Surgical management of cervical spondylotic myelopathy - indications for anterior, posterior or combined procedures for decompression and stabilisation. Acta Neurochir (Wien). 2014;156(2):253-258.

20. Fehlings MG, Arvin B. Surgical management of cervical degenerative disease: the evidence related to indications, impact, and outcome. J Neurosurg Spine. 2009;11(2):97-100.

21. McAfee P, Bohlman H, Ducker T, Ziedman S, Goldstein J. One-stage anterior cervical decompression and posterior stabilization. A study of one hundred patients with a minimum of two years of followup. J Bone Jt Surg Am. 1995;77(12):1791-800.

22. Kim PK, Alexander JT. Indications for circumferential surgery for cervical spondylotic myelopathy. Spine J. 2006;6(6 Suppl):299S-307S.

23. Oglesby M, Fineberg SJ, Patel A a, Pelton M, Singh K. Epidemiological trends in cervical spine surgery for degenerative diseases between 2002 and 2009. Spine Phila Pa 1976. 2013;15(38):1226-32. 24. Heller JG, Edwards CC, Murakami H, Rodts GE. Laminoplasty versus laminectomy and fusion for multilevel cervical myelopathy: an independent matched cohort analysis. Spine (Phila Pa 1976). 
2001;26(12):1330-6. Available at: http://www.ncbi.nlm.nih.gov/pubmed/11426147. 25. Hamanishi C, Tanaka S. Bilateral multilevel laminectomy with or without posterolateral fusion for cervical spondylotic myelopathy: relationship to type of onset and time until operation. J Neurosurg. 1996;85(3):447-51. doi:10.3171/jns.1996.85.3.0447. 26. Butler J, Whitecloud T 3rd. Postlaminectomy kyphosis. Causes and surgical management. Orthop Clin North Am. 1992;23(3):505-11.

27. Cerisoli M, Vernizzi E, Giulioni M. Cervical spine changes following laminectomy. Clinicoradiological study. J Neurosurg Sci. 1980;24(2):63-70. 28. Crandall P, Gregorious F. Long-term followup of surgical treatment of cervical spondylotic myelopathy. Spine (Phila Pa 1976). 1977. Available at: http://journals.lww.com/spinejournal/abstract/ 1977/06000/long_term_follo.... Accessed May 19, 2014.

29. Mikawa Y, Shikata J, Yamamuro T. Spinal deformity and instability after multilevel cervical laminectomy. Spine Phila Pa 1976. 1987;12(1):6-11. 30. Ghogawala Z, Coumans J-V, Benzel EC, Stabile LM, Barker FG. Ventral versus dorsal decompression for cervical spondylotic myelopathy: surgeons' assessment of eligibility for randomization in a proposed randomized controlled trial: results of a survey of the Cervical Spine Research Society. Spine (Phila
Pa 1976). 2007;32(4):429-36.

31. Ghogawala Z, Martin B, Benzel EC, et al. Comparative effectiveness of ventral vs dorsal surgery for cervical spondylotic myelopathy. Neurosurgery. 2011;68(3):622-30; discussion 630-1.

\section{Disclosures}

Virginie LaFage has received research support from DePuy; owns stock in and is on the Board of Directors of Nemaris Inc.; and has speaking and teaching arrangements with Medicrea, DePuy, Nemaris Inc, $\&$ MSD. The other authors declare no relevant financial disclosures.

\section{Corresponding Author}

Peter G. Passias, NY Spine Institute/NYU Medical Center-Hospital for Joint Diseases, 301 E. 17th Street, New York, NY 10003. peter.passias@nyumc.org.

Published 19 June 2015. This manuscript is generously published free of charge by ISASS, the International Society for the Advancement of Spine Surgery. Copyright @ 2015 ISASS. To see more or order reprints or permissions, see http://ijssurgery.com. 